\title{
THE ROUTINE USE OF LUMBAR EPIDURAL ANAESTHESIA IN OBSTETRICS: A CLINICAL REVIEW OF 9,532 CASES
}

S. M. Eisen, M.D.; N. Rosen, M.D.; H. Winesanker, M.D.; K. Hellman, M.D.; H. I. Axelrod, B.A., M.D.; M. Rotenberg, M.D.; A. Relle, M.D.; and E. Sheffman, M.D. ${ }^{1}$

IN OUR SOCIETY, modern woman has learned to expect relief of pain in childbirth. Unfortunately, obstetrical anaesthesia is responsible for a significant proportion of maternal deaths (1). Most of these deaths are due to aspiration of vomited or regurgitated stomach contents $(2,3)$. This accident occurs in the best hospitals despite the training and skill of qualified anaesthetists.

To solve this problem regional anaesthesia has often been suggested, but for various reašons it has never become universally popular. Low spinal anaesthesia (saddle-block) has been used in some centres for years. 'Unfortunately, in many centres, the high incidence of post-spinal headaches $(4,5)$ and some reported serious neurological sequellae (6) have caused it to be shunned by both obstetricians and the public. Pudendal block has been tried, but results have not been consistently good enough to warrant its universal adoption. Recently, several reports $(7,8)$ have appeared in the literature on the use of lumbar epidural anaesthesia in obstetrics. Results appear to be good, but for several reasons the method has been used on only a fraction of the patients delivered in any centre.

Our purpose at this hospital was to investigate the possibility of establishing lumbar epidural anaesthesia as the routine method for relieving pain in childbirth. By routine, we mean that, except when contraindications existed, all mothers would receive this type of anaesthetic for their delivery.

We would not be satisfied with only selected cases, or cases with special indications being anaesthetized in this way. If only 50 per cent of cases are delivered under epidural anaesthesia, we have only reduced the hazards of inhalation anaesthesia by 50 per cent. This we did not consider good enough.

The following reasons are considered by us as contraindications to this method of anaesthesia: (1) refusal of patient to accept this type of anaesthesia; (2) infection of the back area; (3) certain neurological conditions; (4) certain abnormalities of the spinal column; (5) patients with bleeding tendencies or on anticoagulant therapy.

On analysis we found several factors existed which opposed the routine adoption of epidural anaesthesia. We will outline these factors and indicate how they were dealt with in our hospital.

1. Objections of obstetricians. In common with other physicians, obstetricians are inherently suspicious of new methods. They cling to established procedures and require special indications before allowing something new to be tried on their patients. This not only prevents the adoption of any new technique as a

Department of Anaesthesia, New Mount Sinai Hospital, Toronto. 
routine, but also prevents the anaesthetists from using the new technique frequently enough to become proficient in its use. In the period from September, 1953 , to October, 1956, inhalation anaesthesia was the routine method used in our hospital for' obstetrics. During this period we had threè women in whom aspiration of stomach contents occurred. All three were fortunately'saved by timely and intensive treatment, but all three were very close to death. Combined meetings were held of the staffs in obstetrics and anaesthesia to discuss these near deaths. It was agreed that if future catastrophes were to be averted, some alternative to inhalation anaesthesia in obstetrics must be found. Our obstetrical staff was, therefore, entirely co-operative in allowing us to practise epidural anaesthesia on all their patients and were very sympathetic during the early period while we were learning the technique. Furthermore, because we used this new method on all patients we soon became quite proficient.

2. Opposition of anaesthetists. Anaesthetists, too, are reluctant to replace a method in which they have become proficient over the years, with a new technique which requires learning, and in which at first they will exhibit some clumsiness. It was realized that in the early period a few anaesthetic failures, or even one serious complication might spell the doom of the new technique. It was, therefore, decided that in the first week, only the chief of the anaesthetic staff would attempt epidural anaesthesia in the obstetrical cases assigied to him. After this period, he found that the method was not difficult and that of 24 attempted epidurals, 24 successful blocks had been obtained without any apparent complications. In every instance, both obstetrician and patient were pleased. The result of his experiences was then reported to the members of the anaesthetic staff, and it was decided to adopt lumbar epidural anaesthesia as the routine method for obstetrics. In some instances this was done reluctantly at first, but very soon all members were using this method by preference.

3. Objections of the nursing staffs. Like doctors, nurses are inherently opposed to any changes in routine. In the case of epidural anaesthesia several changes were necessary. The nurses had to watch the patients more carefully during labour to allow time for an epidural block. In addition they had to provide a sterile tray and had to position the patient on the table for the procedure. This was done very reluctantly at first. They soon realized, however, that the new technique had advantages. They were spared the emptying of emesis basins at the termination of the anaesthetic and they soon appreciated the advantage to both mother and. baby. The nursing staff at our hospital is now enthusiastic about epidural anaesthesia in obstetrics.

4. Opposition of patients. In this cenfre, many patients usually dread spinal anaesthesia. At the beginning we therefore had to emphasize the fact that this was not a spinal anesthetic. We explained that although this technique meant a "needle in the back," this needle was not introduced as far as it was with a spinal anaesthetic, and that headaches would not result. In addition, most mothers had at first expressed a preference for "going to sleep, so that they would not see what goes on." We explained that they would experience a tremendous thrill when they heard their baby cry as soon as it was born. These first patients were so pleased with their epidural anaesthetic that they told their friends, and soon 
patients arrived asking for this new type of "needle anaesthetic." Now we seldom have a patient who objects. We never force an epidural anaesthetic on a patient who does not agree to have one.

5. Problems in technique. The technique of lumbar epidural anaesthesia (9) as described by previous authors requires an appreciable period of time. Since the exact time of delivery is not predictable, it was apparent at the start that to include all cases, the accepted techniques of epidural anaesthesia would have to be modified so that a block could be performed very quickly. We will, therefore, describe our present technique which we believe has much to recommend it, and which has proved to be entirely safe.

- (a) Scrub. Most authors recommend that the anaesthetist scrub his hands for from 5 to $10 \mathrm{~min}$. and then carefully don a sterile gown and gloves. In this interval a quick multipara might deliver her baby without the advantage of an anaesthetic, or the anaesthetist might have to abandon his scrub and quickly place a mask over her face. In this hospital we neither scrub nor gown. We do, however, wear a cap and mask and put on a pair of sterile rubber gloves, a procedure which requires only a few seconds. In view of the fact that a surgical scrub is deliberately omitted, we are particularly meticulous in putting on our sterile rubber gloves. We realize that we may be criticized for inviting infection, but in our 9,532 obstetrical cases and 5,091 surgical cases not a single infection has occurred. To us it appears that inhalation anaesthesia presents a far greater hazard.

(b) Preparation of back. At first we used coloured alcoholic solutions of the popular antiseptics. A few mild skin reactions occurred in the first few months. We changed to Cetavlon (a detergent), and have used it exclusively since then. The Cetavlon is rubbed on the back for a few seconds. The back is then dried rapidly with sterile gauze. This drying is important because: (i) it is undesirable to introduce detergent in to the epidural space and cause possible nerve damage (9), and (ii) detergent renders the gloves slippery and makes handling of the epidural needle more difficult. As stated previously, the lack of infection has proved this skin preparation entirely satisfactory.

(c) Method of finding epidural space. Most authors recommend the "change in resistance" (9) technique with either air or fluid in the syringe. A few recommend the "hanging drop" method, and a very few recommend the "touch" method. Our method combines features of all these three previously recommended methods. After a preliminary skin wheal over the interspace between L3-L4 or L4-L5, a 16- or 17-gauge Tuohy needle is introduced into the interspinous ligaments. A $20 \mathrm{cc}$. syringe filled with lidocaine 2 per cent (Xylocaine) is attached, and the resistance to injection is felt. This manœuvre also provides a drop of fluid in the hub of the needle. Some of our staff anaesthetists omit this step, and instead fill the hub from the syringe to which a hypodermic needle is attached, With the syringe detached from the Tuohy needle, the hub of the needle is grasped between the thumb and index fingers of the right hand. The ulnar side of the left hand is then placed against the patient's back, and the shaft of the needle is held between the thumb and fingers of the left hand. The left hand is used to guide the needle in the proper direction, and to prevent too 
rapid or jerky advance of the needle by the right hand. One soon learns to judge (by sense of touch) when the thick ligamentum flayum is reached, and then it is pierced with a steady pressure. In over 80 per cent of cases the drop of fluid in the needle hub is now sucked in, and thus announces that the epidural space has been reached. In the other 20 per cent of cases one's sense of touch makes the same announcement. In either case the ringeful of lidocaine is now connected to the needle, and the lack of resistance to injection corroborates the proper placement of the needle. There is no test dose and no waiting period. Time cannot be spared. Should the dura be inadvertently punctured, our large needles provide a rapid outward flow of spinal fluid to give us due warning. The large size and shape (Huber point) of the Tuohy needle makes it very easy to deviate to one or other, side of the mid-line. With practice this tendency can be corrected. However, if this does occur and the lamina is reached instead of the ligamentum flavum, valuable information has been gained, because the depth of the ligamentum flavum has been indicated for that particular patient. Slight redirection of the needle will find the ligamentum flavum and the epidural space.

Using this technique the members of our staff can usually introduce a needle into the epidural space within three minutes of entering the delivery room. In a very few patients, because of anatomical difficulties, it occasionally takes longer, but this occurs only rarely.

(d) Timing. An important feature that must be learned is at what stage in labour to begin the epidural anaesthetic. If given too soon, the anaesthetic will wear off before the patient delivers, and necessitate the repetition of the anaesthetic. This does no harm, but the patient is subjected to a second needle, and the obstetrician may become suspicious that the anaesthetic has slowed the progress of labour. On the other hand, waiting too long may not give the epidural time enough to give complete relief of pain before the patient delivers. Obviously as one becomes more experienced in the method, the procedure takes less time, and one can wait until later in the course of labour before proceeding with the anaesthetic. With primiparas we wait not only until caput is visible, but until caput is well down on the perineum. These patients will rarely precipitate. An obstetrician who wishes to save the patient some suffering may request an earlier anaesthetic, but in this instance he may have to apply forceps. Patients are able to bear down after they receive an epidural anaesthetic, and some of them do so very effectively if requested. However, the anaesthetic does inhibit the urge to push, and an unco-operative patient will not do so.

Multiparas present more of a problem. We have found that a more important criterion exists than the degree of dilatation of the cervix, namely the degree of descent of the head (or station). With the head at the ischial spines or above, even with full cervical dilatation, it may take two hours or more before the patient is ready for delivery. On the other hand, we have administered epidural anaesthetics to patients with only $4 \mathrm{~cm}$. dilatation when the head had descended to station 2 plus or lower, and have then found that the cervix has rapidly "melted away" soon after the epidural was given, and that the patient was ready for delivery in a few minutes. In the last analysis, judgment as to when to give the epidural is an individual problem, and can only be learned after much 
experience. After introducing the lidocaine in to the epidural space, the pains of the contractions disappear in 3 to $4 \mathrm{~min}$. However, it usually takes 10 to $15 \mathrm{~min}$. for full perineal anaesthesia to develop. We have found it profitable to adlminister an epidural anaesthetic in cases when it is quite obvious that the patient will not wait 10 to $15 \mathrm{~min}$. for delivery. Nitrous oxide or cyclopropane administered only to the stage of analgesia during delivery of the head will render childbirth painless. The epidural will be effective for the repair of the episiotomy or laceration. We have never seen vomiting or regurgitation occur with an inhalation anaesthetic of such short duration.

\section{RESULTS}

Our purpose, as stated previously, was to investigate the possibility of establishing lumbar epidural anaesthesia as the routine method for vaginal deliveries. From the table it may be seen that in September, 1956, the month before we

TABLE I

RESULTS

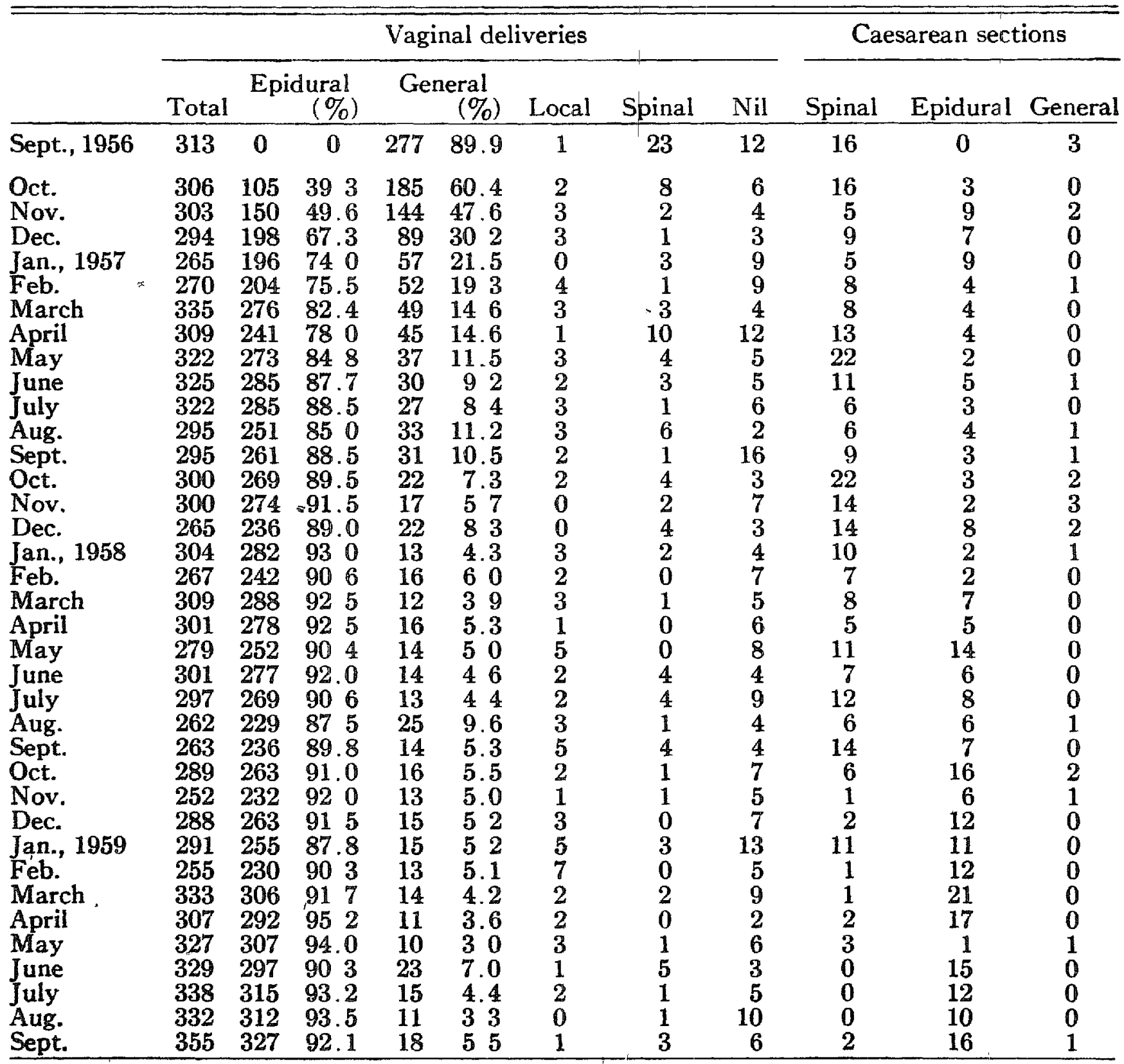

Total epidural anaesthetics: 9,532-9,256 vaginal deliveries; 276 Caesarean sections. 
began practising this method, general anaesthesia was used in 89.9 per cent- of cases. Within six months, lumbar epidural anaesthesia was being used for about 80 per cent of vaginal deliveries, and general anaesthesia for about only 15 per cent. After one year, epidural anaesthesia was being used in 90 per cent of cases and general anaesthesia in less than 10 per cent. We now find that general anaesthesia is only used in about 5 per cent of cases.

\section{Complications}

The two most classically dreaded complications in epidural anaesthesia are: massive or total spinal anaesthesia $(10,11)$, and convulsions $(10,11)$.

\section{Massive or Total Spinal Anaesthesia}

This occurred four times in our 9,532 cases, or 0.04 per cent. It is caused by the addition of a large volume of local anaesthetic drug to the spinal fluid in the subarachnoid space. Ouruse of large gauge needles for epidural anaesthesia helps to warn us if the dura is accidentally punctured. At first it was our practice to proceed with epidural anaesthesia in another interspace when the dura was accidentally punctured. However, in the early months of our experience, two cases of massive spinal anaesthesia resulted on successive days when this was done. Since then it is our practice to abandon lurnbar epidural anaesthesia if inadvertent dural puncture occurs. Instead, we inject 3 to 4 cc. of lidocaine 2 per cent into the spinal fluid and thus purposely administer a spinal anaesthetic.

Two other cases of total sinal anaesthesia occurred in which there was no evidence of dural puncture present to warn us. In all cases the patients rapidly lost consciousness and spontaneous respirations ceased. These patients were immediately ventilated with 100 per cent oxygen. An intravenous infusion was started and vasopressors were given intravenously when indicated. In all instances consciousness and spontaneous respiration was resumed in from 60 to $90 \mathrm{~min}$. There were no adverse effects observed in mother or infant in any of the four instances.

\section{Convulsions}

Convulsions occurred six times, or 0.063 per cent. These are a toxic reaction to the local anaesthetic drug. In all cases patients were ventilated with oxygen, with either a face mask or an endotracheal tube. Succinylcholine and/or intravenous barbiturate were given if adequate oxygenation was not possible because of convulsions. All convulsions were controlled within $5 \mathrm{~min}$. None of the six mothers and infants showed any deleterious effects whatsoever.

It is gratifying that these dreaded complications occurred so infrequently, and that when they did occur, they all responded so favourably to treatment.

We wish to stress, however, that these complications can and do occur. For this reason lumbar epidural anaesthesia should never be attempted by the untrained or occasional anaesthetist, who is not able to treat these complications. 


\section{Less Serious Complications}

Hypotension. This occurs more gradually and is usually of a lesser degree than the hypotension associated with spinal anaesthesia. We have decreased its incidence by routinely placing the patient's legs up in stirrups immediately after the drug is injected into the epidural space. Despite this manœuvre nearly all sases experience a slight blood pressure drop, usually of about $10-20 \mathrm{~mm}$ mercury. We do not administer a vasopressor drug unless the systolic blood pressure falls below $80 \mathrm{~mm}$. mercury. Neither mother nor infant seems to be adversely affected by hypotension of this degree. We have administered vasopressors 130 times in our 9,532 cases, or 1.363 per cent.

In pre-eclamptic patients who have not responded to routine medical therapy, we have utilized the hypotensive effect of epidural anaesthesia with what appears to be good results. We introduce a vinyl plastic catheter into the epidural space during labour, and give repeated doses of lidocaine 0.5 per cent until the desired degree of hypotension is achieved. When the patient is ready for delivery we introduce lidocaine 2 per cent via the same epidural catheter, to achieve adequate obstetrical anaesthesia.

Drowsiness. This occurs fairly frequently. It is, we believe, in part a toxic manifestation of lidocaine. In other cases it is due to the analgesic and sedative drugs which the patients have received earlier in labour. With relief of pain following the epidural anaesthetic, the sedative effect of these drugs becomes more pronounced and renders the patient drowsy. We have found drowsiness an advantage rather than a disadvantage.

Shivering. A few patients experience interise shivering. We have, however, seen it in some patients before the epidural anaesthetic has been administered. We do not know its significance, but it apparently causes no harm.

Vomitnng. This seldom occurs with epidural anaesthesia. When it does occur it may be associated with (a) a rapid fall of blood pressure, $(b)$ a rapid rise of blood pressure due to the administration of a vasopressor drug, or (c) most frequently, after the administration of an ergot derivative. Vomiting has hever been severe enough to constitute a problem.

Arrest or slowing of labour. From our observations on this large series, it is our impression that epidural anaesthesia does not interfere with the progress of labour. Good contractions still occur after the anaesthetic has been administered. It is also our impression that dilatation of the cervix is more rapid after an epidural anaesthetic. The desire to bear down does disappear, but a co-operative patient can still push effectively, if so instructed. In the early days of our series, a few epidural anaesthetics were administered to patients in whom full dilatation of the cervix had occurred, but in whom the foetal head had not descended below the level of the ischial spines. In some cases the anaesthetic wore off before the patient was ready for delivery. The obstetricians, in these instances, tended to blame the anaesthetic for slowing the progress of labour. Since then, we have seen many similar cases of patients with full dilatation of the cervix, and a high foetal head. No anaesthetic has been given to these latter patients, yet they were not ready for delivery for two hours or more. We therefore think that the first cases represent improper timing of the anaesthetic, but that no slowing of labour 
occurred. A repeated epidural anaesthetic in these cases caused no apparent harm.

Improper timing. This occurred 31 times, er 0.33 per cent. It includes those instances in which the epidural anaesthetic was given too soon and the effect had worn off before the patient was delivered and the perineum repaired.

Inadvertent dural puncture. This has occurred 78 times, or 0.82 per cent. Included in this series are epidural anaesthetics attempted by interns and residents with no previous experience and by members of our staff when they were neophytes in epidural anaesthesia. Dural punctures decrease in frequency with the increasing experience of the anaesthetist in epidural anaesthesia. They will, however, occur to some extent to even the most experienced. We use large bore needles (16 or 17 guage), so that inadvertent dural puncture is usually $\mid$ very evident when it occurs.

Headache. Headaches are encountered very infrequently as sequellae of epidural anaesthesia (11). Most of them occur in conjunction with inadvertent dural puncture. Some cases have occurred, however, where no dural puncture had taken place.

Other neurological sequellae. We have no accurate statistics on these available from our records. We have, however, from the start of this series asked the obstetricians to report these cases to us and they have been very co-operative in doing so. There have been 16 paraesthesias reported, and 9 patients reported who displayed small areas of anaesthesia. These occurred usually over the lateral aspect of the thigh. Most disappeared in three or four days, but in at least two instances they persisted for several weeks. All were transient, and none was serious. We must, however, report a paraplegia which occurred recently following an epidural anaesthetic for surgery (not in this obstetrical series). The paraplegia was rather bizarre in that motor paralysis occurred but no sensory impairment was evident. The patient is making a good recovery.

Infection. It is gratifying that although our technique does not include a surgical scrub of the hands, or donning of a sterile gown, in our 9,532 obstetrical cases and 5,091 surgical cases, not a single case of infection has occurred.

Backache. A few patients have complained of backache following this type of anaesthesia. This complaint is common in obstetrical patients regardless of the type of anaesthesia received.

\section{IMPRESSIONS}

After three years of using lumbar epidural anaesthesia as the routine anaesthetic in obstetrics, our entire obstetrical and anaesthetic staffs are unanimous in their approval. We realize that it has shortcomings but believe it to be the very best anaesthetic for obstetrics available today. It eliminates the threat of maternal death through aspiration of stomach contents. It provides excellent anaesthesia. Precipitate deliveries are reduced in number. Infants are not depressed. In a busy case room a single anaesthetist can cope with the three or four mothers who are suddenly ready for delivery: Complications have been few. Patients love it. 


\section{SUMmaRy}

A report is given of an attempt by the anaesthetic staff of the New Mount Sinai Hospital, Toronto, to evaluate lumbar epidural anaesthesia as a routine anaesthetic in obstetrics. This was done primarily in order to eliminate the threat of maternal mortality through the aspiration of stomach contents. To anaesthetize all obstetrical patients in this manner it was necessary to obtain the full co-operation of the entire obstetrical, anaesthetic, and nursing staffs. It was also necessary to modify the technique of lumbar epidural anaesthesia so that the procedure takes only about three minutes. Surgical scrub of the hands and the donning of a sterile gown have been omitted from the technique, with no evidence of infection in the reported 9,532 obstetrical cases and 5,091 surgical cases. The classically dreaded complication of total spinal anaesthesia occurred four times or 0.42 per cent, and that of convulsions occurred six times or 0.63 per cent. All cases responded to therapy without apparent harm to mother or infant. Lesser complications occurred infrequently and have been discussed in the paper. There were no anaesthetic deaths in this series. Labour is apparently not slowed by epidural anaesthesia and dilatation of the cervix seems to be hastened.

After three years of this experiment, we now use lumbar epidural anaesthesia for over 90 per cent of our vaginal deliveries, and general anaesthesia for less than 5 per cent.

The obstetrical and anaesthetic staffs of our hospital believe that although lumbar epidural anaesthesia in obstetrics has some shortcomings it is the most desirable obstetrical anaesthetic available today.

\section{RÉSUMÉ}

Le personnel du service d'anesthésie de l'hôpital New Mount Sinai, Toronto, présente le résultat d'une tentative d'appréciation de l'usage de routine de l'anesthésie épidurale lombaire en obstétrique. Le premier but de cette pratique a été d'éliminer la mortalité maternelle qui survient à la suite de regurgitation et d'aspiration bronchique du contenü gastrique. Pour réussir à administrer cette anesthésie à toutes les malades, il faut absolument être assuré de la collaboration de tout le personnel obstétrical, anesthésique ou infirmière. De plus, il al fallu modifier la technique anesthésique pour qu'elle ne dépasse pas trois minutes. Le brossage chirurgical des mains et la blouse stérile ont été laissés de côté et, sur 9532 cas d'obstétrique et 5091 cas de chirurgie, on ne nous a pas signalé d'infection. La complication classique d'anesthésie rachidienne totale est survenue quatre fois soit $0.42 \%$ et celle de convulsions est survenue six fois soit $0.63 \%$. La thérapeutique appliquée a été efficace et ni la mère ni l'enfant ne porte de sequelle. Des complications de moindre importance ont été observées de temps en temps, on les mentionne dans le travail. Dans cette série, aucune mort n'est survenue. Le travail, selon toute apparence, n'est pas ralenti par l'anesthésie épidurale et la dilatation du col semble accélérée.

Après avoir procédé de cette façon depuis trois ans, nous continuons à employer l'anesthésie épidurale dans $90 \%$ de nos accouchements vaginaux et nous employons l'anesthésie générale chez moins de $5 \%$ de nos cas. 
Le personnel des deux services: d'obstétrique et d'anesthésie de notre hôpital s'accordent à dire que, bien que l'anesthésie épidurale en obstétrique aie quelques inconvénients, elle demeure l'anesthésie obstétriçale la plus souhaitable à notre disposition aujourd'hui.

\section{REFERENCES}

1. Merrell, R. B., \& Hingson, R. A. Study of Incidence of Maternal Mortality from Aspira. tion of Vomitus during Anesthesia Occurring in Major Obstetric Hospitals in United States. Anesth. \& Analg. 31 : 121 (May-June, 1951).

2. Edwards, G.; Morton, H. I. V.; Pask, E. A.; \& Włlie, W. D. Deaths Associated with Anaesthesia. Anaesthesia 11:194 (July, 1956).

3. Hingson, R. A., \& Hellman, I. H. Organization of Obsitetrical Anesthesia on a 24 hr. Basis in a Large and a Small Hospital. Anesthesiology 12: 745:(1951).

4. Huston, J. W., \& Lebhartz, T. B. Incidence of Post-Partum Headaches after Spinal Anaesthesia. Am. J. Obst. \& Gynec. 63:139. (1952).

5. Vandam, L. D., \& DRIPPs, R. D. Long Term Follow-up of Patients who Received 10,000 Spinal Anesthetics: Syndrome of Decreased Intra-Cranial Pressures. J.A.M.A. 161: 586 (1956).

6. Gilbert, R. G. B. Neuroblogical Complications of Spinal Anaesthesia. Canad. Anaesth. Soc. J. 2: 116 (1955).

7. Chaplin, Rf A., \& Renwick, W. A. Lumbar Epidural Anaesthesia for Vaginal Delivery. Canad. Anaesth. Soc. J. 5: 414 (Oct., 1958).

8. Fleming, S. A., \& Campbell, S. M. Epidural Anesthesia in Obstetrics. Anesth. \& Analg. 30: 2 (March-April, 1958).

9. Brqpage, P. R. Spinal Epidural Analgesia, 1st ed. Edinburgh and London: E. \& S. Livingstone Ltd. (1954).

10. Moore, D. C. Complications of Regional Anesthesia, 1st ed. Springfield: Thomas (1955).

11. Bonica, John J.; Backup, Phillip, N.; Anderson, Charles E.; Hadfield, Dale; \& Crepps, William F. Peridural Block: Analysis of 3,637 Cases and a Review. Anesthesiology 18 (5) (Sept.-Oct., 1957). 